\title{
PENGARUH METODE ROLE PLAYING TERHADAP PEMBELAJARAN DRAMA
}

\author{
Nurul Anggita, H. Rustam Efendy Rasyid, dan Aswadi \\ Universitas Muhammadiyah Sidenreng Rappang \\ Jl. Angkatan 45 No 1A Lautang Salo Rappang, Pancarijang, Sidenreng Rappang \\ nurul anggita@gmail.com
}

\begin{abstract}
Abstrak: Pengaruh Metode Role Playing terhadap Pembelajaran Drama. Penelitian ini bertujuan untuk mengetahui pengaruh metode role playing terhadap pembelajaran drama pada siswa kelas XI MIPA.3 SMA Negeri 6 Sidrap 2018/2019. Desain penelitian ini adalah penelitian eksperimen semu dengan jumlah sampel sebanyak 32 siswa. Data dikumpulkan melalui teknik dokumentasi dan tes. Hasil analisis data menunjukkan bahwa nilai rata-rata kelompok eksperimen lebih tinggi dibandingkan dengan nilai rata-rata kelompok kontrol $(78,12>73,75)$. Hal ini menunjukkan bahwa hipotesis alternatif yang menyatakan "Ada pengaruh metode role playing terhadap pembelajaran drama siswa kelas XI MIPA.3 SMA Negeri 6 Sidrap", diterima. Oleh karena itu, hipotesis nihil yang berbunyi "Tidak ada pengaruh metode role playing terhadap pembelajaran drama siswa kelas XI MIPA.3 SMA Negeri 6 Sidrap", ditolak.
\end{abstract}

Kata kunci: drama, pembelajaran, role playing

\begin{abstract}
The Effect of Role Playing Method on Drama Learning. his study aims to determine the effect of the role playing method on drama learning in class XI MIPA.3 students of SMA Negeri 6 Sidrap 2018/2019. This study was quasi-experimental research with sample 32 students. Data collected through documentation and test techniques. The results of data analysis showed that the average of the experimental group was higher than control group $(78,12>73,75)$. This shows that the alternative hypothesis "There is an influence of the role playing method on the learning of drama class XI MIPA.3 students of SMA Negeri 6 Sidrap", was accepted. Therefore, the null hypothesis "There is no effect of the role playing method on the drama learning in class XI MIPA.3 students of SMA Negeri 6 Sidrap ", was rejected.
\end{abstract}

Keyword: drama, learning, role playing

Sastra merupakan hasil cipta yang mengungkapkan pribadi manusia berupa pengalaman, semangat, ide, pemikiran, dan keyakinan dalam suatu gambaran konkret yang mampu membangkitkan gairah yang dapat tersalurkan dengan alat bahasa. Dengan melihat dan mendengarkan karya sastra yang indah, maka keindahan tersebut dapat menggetarkan sukma, dapat menimbulkan keharuan, kemesraan, kebencian, atau pandangan hati, gemas, dan dendam bagi penikmatnya.

Salah satu hasil dari karya sastra ialah drama, di mana drama adalah salah satu genre sastra yang hidup dalam dua dunia, yaitu seni sastra dan seni pertunjukan atau teater. Orang yang menganggap drama sebagai seni pertunjukkan akan membuang fokus itu sebab perhatiannya harus dibagi rata dengan unsur lainnya (Mulyana, 1997).

Pembelajaran drama di sekolah umumnya belum berjalan seperti yang diharapkan. Hal ini perlu mendapatkan perhatian khusus sebab kondisi belajar siswa di sekolah kurang maksimal dalam belajar contohnya kurangnya percaya diri siswa, kegiatan belajar tidak menarik bagi siswa dan tentu saja hal tersebut berdampak kurang baik 
pada hasil pembelajaran drama, khususnya di Sekolah Menengah Atas. Oleh karena itu, guru membutuhkan metode baru untuk merangsang anak didik guna keberhasilan pembelajaran drama di sekolah. Metode merupakan cara teratur yang digunakan untuk melaksanakan suatu pekerjaan agar tercapai sesuai dengan yang dikehendaki atau cara kerja yang bersistem untuk memudahkan pelaksanaan suatu kegiatan guna mencapai tujuan yang ditentukan (Depdikbud, 2003).

Salah satu metode yang dapat digunakan oleh guru dalam memperbaiki kualitas pembelajaran drama adalah metode role playing. Metode ini lebih menekankan pada masalah dalam pertunjukan bukan pada kemampuan pemain dalam melakukan peran. Sehingga siswa dapat memahami karakter dari setiap peran yang dilakonkan. Hasil penelitian terdahulu menyimpukan bahwa pembelajaran yang menggunakan metode role palying (bermain) dapat memengaruhi motivasi belajar siswa dan meningkatkan hasil belajar siswa (Rahmi, 2014; Rosmiati, 2012; Silaent, 2014).

\section{METODE}

Pendekatan yang digunakan dalam penelitian ini adalah pendekatan kuantitatif. Data penelitian yang digunakan berupa angka-angka serta analisis, sehingga disebut dengan metode kuantitatif. Analisis data bersifat kuantitatif/statistik dengan tujuan menguji hipotesis yang sudah ditetapkan sebelumnya (Sugiyono, 2010). Jenis penelitian yang digunakan adalah eksperimen, penelitian ini menguji secara langsung pengaruh suatu variabel terhadap variabel lain (Sukmadinata, 2010). Variabel dalam penelitian ini yakni: (a) penggunaan metode role playing dalam pembelajaran sebagai variabel bebas dan (b) pembelajaran drama dalam mata pelajaran Bahasa Indonesia sebagai variabel terikat.

\section{HASIL DAN PEMBAHASAN \\ Hasil Penelitian}

Berikut ini disajikan nilai hasil belajar siswa pada pembelajaran drama dengan menggunakan metode role playing siswa kelas XI MIPA.3 SMA Negeri 6 Sidenreng Rappang kelompok eksperimen dan kelompok kontrol.

Tabel 1 Nilai Hasil Belajar Kelompok Eksperimen dan Kelompok Kontrol

Kelompok Eksperimen

Kelompok Kontrol

\begin{tabular}{cccccc}
\hline Kode Responden & Skor & Nilai & Kode Responden & Skor & Nilai \\
\hline 1 & 16 & 80 & 2 & 18 & 80 \\
\hline 3 & 16 & 80 & 4 & 18 & 90 \\
\hline 5 & 18 & 90 & 6 & 18 & 90 \\
\hline 7 & 14 & 70 & 8 & 14 & 70 \\
\hline 9 & 16 & 80 & 10 & 14 & 70 \\
\hline 11 & 14 & 70 & 12 & 16 & 80 \\
\hline 13 & 18 & 90 & 14 & 14 & 70 \\
\hline 15 & 18 & 90 & 16 & 16 & 80 \\
\hline 17 & 14 & 70 & 18 & 12 & 70 \\
\hline 19 & 16 & 80 & 20 & 12 & 60 \\
\hline 21 & 16 & 80 & 22 & 16 & 60 \\
\hline 23 & 18 & 90 & 24 & 12 & 60 \\
\hline 25 & 18 & 90 & 26 & 16 & 80 \\
\hline 27 & 12 & 60 & 28 & 14 & 70 \\
\hline 29 & 14 & 70 & 30 & 14 & 70 \\
\hline 31 & 12 & 60 & 32 & &
\end{tabular}


Tabel 2 Tabel Kerja SPSS 21

\begin{tabular}{lcc}
\hline \multicolumn{3}{c}{ Report } \\
\hline Mean & Kontrol & Eksperimen \\
\hline $\mathrm{N}$ & 73,75 & 78,12 \\
\hline Std. Deviation & 16 & 16 \\
\hline Std. Error of Mean & 9,57 & 10,46 \\
\hline Median & 2,39 & 2,61 \\
\hline Maximum & 70,00 & 80,00 \\
\hline Minimum & 90,00 & 90,00 \\
\hline Sum & 60,00 & 60,00 \\
\hline
\end{tabular}

Sumber: Hasil SPSS 21

Tabel 2 menunjukkan nilai rata-rata kelompok eksperimen lebih tinggi disbanding dengan nilai rata-rata kelompok kontrol $(78,12>73,75)$

\section{PEMBAHASAN}

Berdasarkan hasil penelitian data diperoleh gambaran yang menunjukkan bahwa nilai rata-rata kelompok eksperimen adalah 78,12 sedangkan nilai rata-rata kelompok kontrol adalah 73,75. Nilai empiris tersebut menunjukkan bawha nilai rata-rata hasil belajar siswa pada kelompok eksperimen lebih besar daripada kelompok kontrol $(78,12>73,75)$. Oleh karena itu hipotesis alternatif $\left(\mathrm{H}_{\mathrm{a}}\right)$ yang berbunyi "Ada pengaruh metode role playing terhadap pembelajaran drama siswa kelas XI SMA Negeri 6 Sidenreng Rappang" diterima. Sedangkan hipotesis nihil $\left(\mathrm{H}_{\mathrm{o}}\right)$ yang berbunyi "Tidak ada pengaruh metode role playing terhadap pembelajaran drama siswa kelas XI SMA Negeri 6 Sidenreng Rappang" ditolak. Berdasarkan dari hasil tersebut, disimpulkan bahwa ada pengaruh penggunaan metode role playing terhadap pembelajaran drama siswa kelas XI SMA Negeri 6 Sidenreng Rappang.

Hasil penelitian ini didukung oleh penelitian sebelumnya, yaitu penelitian dilakukan oleh Silaent (2014) yang berjudul "Penerapan Metode Role Playing untuk Meningkatkan Motivasi dan Hasil Belajar Siswa VIII.A SMP Negeri 1 Long Ikis Pada Materi Sistem Peredaran Darah Manusia". Penelitian ini mengemukakan bahwa rata-rata skor postes kelas eksperimen yaitu 76,43, sedangkan rata-rata skor kelas control yaitu 69,00 . Dari hasil pengujian hipotesis diperoleh nilai $\mathrm{t}_{\text {hitung }}=4,66$ dan $\mathrm{t}_{\text {tabel }}=2,00$. Data ini menunjukkan bahwa $t_{\text {hitung }}>t_{\text {tabel }}$, maka $\mathrm{H}_{0}$ ditolak dan $\mathrm{H}_{1}$ diterima. Maka dapat disimpulkan bahwa pembelajaran yang menggunakan metode role playing dapat mempengaruhi motivasi belajar IPS siswa kelas V (Silaent, 2014). Hasil penelitian Rahmi juga menunjukkan bahwa pembelajaran IPS dengan menggunakan metode role playing berpengaruh terhadap motivasi belajar siswa kelas V (Rahmi, 2014). Hasil penelitian Rosmiati (2012) menyimpulkan bahwa penggunaan metode role playing dalam pembelajaran menciptakan adanya eksistensi kegiatan belajar mengajar dengan kurikulum; keaktifan siswa dalam pembelajaran meningkat; dan keterampilan berbicara pada aspek isi, aspek penggunaan bahasa dan aspek performansi meningkat (Rosmiati, 2012).

\section{PENUTUP}

Berdasarkan hasil temuan dari keseluruhan data yang diperoleh peneliti maka dapat disimpulkan bahwa pembelajaran drama dengan menggunakan metode role playing berpengaruh terhadap hasil belajar siswa. Hal ini dapat dilihat dari data hasil hasil belajar siswa pada pembelajaran drama dengan menggunakan metode role playing lebih tinggi dibandingkan data hasil belajar siswa pada pembelajaran drama dengan tidak menggunakan metode role playing $(78,12>73,75)$. Berdasarkan kesimpulan tersebut, penulis menyarankan agar pihak sekolah hendaknya memberikan masukan kepada guru-guru SMA Negeri 6 Sidrap agar dalam proses pembelajaran di kelas menggunakan metode ini di dalam pembelajaran drama. 


\section{DAFTAR PUSTAKA}

Depdikbud. (2003). Kamus Besar Bahasa Indonesia. Jakarta: Balai Pustaka.

Mulyana. (1997). Budaya Krisan. Yogyakarta: Kanisus.

Rahmi, A. (2014). Penggunaan Metode Role Playing terhadap Motivasi Belajar IPS Siswa Kelas V SDN Pekayon Bekasi Jawa Barat. Jakarta: UIN Syarif Hidayatullah Jakarta.

Rosmiati, M. (2012). Penerapan Metode Bermain Peran (Role Playing) dalam Peningkatan Keterampilan Berbicara Siswa Kelas V MI Pangkalan Kota Sukabumi. Jakarta: Fakultas Ilmu Tarbiyah dan Keguruan, UIN Syarif Hidayatullah.

Silaent. (2014). Penerapan Metode Role Playing untuk Meningkatkan Motivasi dan Hasil Belajar Siswa VIII.A SMP Negeri 1 Long Ikis pada Materi Sistem Peredaran Darah Manusia. ..... ....

Sugiyono. (2010). Metode Penelitian Kuantitatif, Kualitatif, dan R\& D. Bandung : Alfabeta. Sukmadinata, N. S. (2010). Metode Penelitian Pendidikan. Bandung: PT Remaja Algesindo. 